\title{
Manipulating rainfall to study symptom expression of Botrytis cinerea infection in wine grapes
}

\author{
G.N. Hill, W.R. Henshall and R.M. Beresford \\ The New Zealand Institute of Plant \& Food Research Limited, Private Bag 92169, Auckland \\ Mail Centre, Auckland 1142, New Zealand \\ Corresponding author: gareth.hill@plantandfood.co.nz
}

\begin{abstract}
Botrytis cinerea infection of wine grapes can result in a variety of symptoms. The most common symptom is botrytis bunch rot (BBR), where infected berries rot and shrivel, and eventually produce fungal sporulation. Another symptom is slip skin, where the skins of infected ripe berries slide easily from the pulp. It is hypothesised that a reduction in osmotic potential in grape berries due to late-season rainfall leads to slip skin symptom development. Hyphal growth of $B$. cinerea on osmotically adjusted agar was inhibited at osmotic potentials associated with near-ripe berries. Vine sheltering was used in a research vineyard to manipulate rainfall artificially and to alter berry sugar content in Vitis vinifera Sauvignon blanc vines, with the aim of increasing osmotic potential and altering symptom expression. Both BBR and slip skin symptoms were affected by the various sheltering conditions, with sheltered vines having lower BBR and higher slip skin at harvest.
\end{abstract}

Keywords grey mould, slip skin, brix, image analysis, water potential.

\section{INTRODUCTION}

Botrytis cinerea is one of the most economically damaging fungal pathogens of wine grapes (Loschiavo et al. 2010). Infected wine grapes most often exhibit symptoms known as botrytis bunch rot (BBR), where infected berries rot and shrivel, and eventually produce fungal sporulation (Wilcox et al. 2015). A less common symptom, known as 'slip skin', results when the skins of infected berries slide off when pressure is applied, leaving the seeds and pulp attached to the rachi (Nelson 1956). While BBR symptoms are visible and can be detected throughout most of the ripening period, slip skin symptoms do not appear until close to harvest. Despite both these symptoms being prevalent throughout the wine industry, it is still largely unclear why $B$. cinerea infection results in BBR or slip skin.

Botrytis bunch rot is a gradual disease that can be detected close to veraison. The disease increases at a reasonably steady rate in the absence of effective management (Beresford et al. 2006). It is usually easy to identify and quantify BBR, either through visual assessments or using image analysis (Hill et al. 2010; Hill et al. 2014a). Conversely, slip skin is undetectable without physical assessment of berries. This disease develops rapidly in the wake of heavy, late-season rainfall, although there is little research published on this symptom.

Due to the apparent development of symptoms following late-season rainfall, we propose the hypothesis that latent $B$. cinerea infections are inhibited by the osmotic 
potential of grape berries, as sugars increase during ripening. Osmotic potential refers to "the maximum theoretical suction that can be developed in a solution as a result of osmosis when the solution is placed in an osmometer surrounded by pure water", and high sugar concentrations result in low osmotic potentials (Taiz \& Zeiger 1998). The osmotic potential of grape berries during ripening decreases from -1 $\mathrm{MPa}$ at véraison to $-4 \mathrm{MPa}$ at harvest (Diakou et al. 1997; Tyerman et al. 2004). Inhibition of in vitro growth on osmotically adjusted media has been demonstrated for different fungi, including Armillaria mellea (Whiting \& Rizzo 1999) and Aspergillus nidulans (Beever \& Laracy 1986).

For an increase in osmotic potential due to rainfall to stimulate slip skin symptom development, water uptake by grapevines needs to enter the berries to affect sugar concentration. Previous research suggested the closing off of berry xylem cells prior to véraison would isolate the berry from the parent plant and prevent water uptake into the berry (McCarthy \& Coombe 1999; Rogiers et al. 2001). However, more recent studies have concluded that the xylem remains intact and that berries are able to take up water post-véraison (Bondada et al. 2005; Keller et al. 2006; Choat et al. 2009). Studies have also found that detached berries are able to take up water, through either the skins or the pedicels (Clarke et al. 2010; Becker et al. 2012).

In the present study, a field trial was carried out where vine shelters were used in a vineyard to manipulate rainfall artificially, and to alter the water uptake in grapevines. This aimed to investigate the effects of rainfall during different parts of the season and water uptake on $B$. cinerea symptom development.

\section{MATERIALS AND METHODS Trial setup}

A field trial was carried out at the Plant \& Food Research Research vineyard at Pukekohe $\left(37.203^{\circ} \mathrm{S}, \quad 174.864^{\circ} \mathrm{E}\right)$ using Vitis vinifera Sauvignon blanc vines in the 2016/17 growing season. Three vine rows were used as replicate blocks. Within each row, one plot was assigned to each of three grapevine phenological stages for shelter installation: flowering onwards, prebunch closure onwards and véraison only. Vines in each plot were designated as one of three sheltering conditions based on their position relative to the shelter: unsheltered (outside the shelter; two per plot), partially sheltered (half vine under shelter; two per plot), and sheltered (directly under shelter; one per plot).

\section{Sheltering}

Nine steel-framed, polyethylene (PE)-covered gazebos were erected as vine shelters in three plots at each of three phenological stages: flowering on 20/12/2016, pre-bunch closure (PBC) on $25 / 01 / 2017$ and véraison on $21 / 02 / 2017$. Shelters were anchored with ropes to trellis posts and all joints reinforced with duct tape. All shelters remained in the vineyard until removal on 04/04/2017 during late-ripening. An additional tenth shelter was set up outside the trial prior to flowering on $07 / 12 / 2016$, under which weather monitoring equipment was installed.

\section{Osmotically adjusted media}

Malt extract agar (MEA; Oxoid Ltd., Basingstoke, Hampshire, UK) was osmotically adjusted to $-0.5,-1.0,-2.0,-3.0$ and $-4.0 \mathrm{MPa}$ by adding, respectively, $0.00,0.71,2.00$, and $3.29 \mathrm{~g}$ of $\mathrm{NaCl}$ per $100 \mathrm{~mL}$ of MEA (known baseline osmotic potential of $-0.5 \mathrm{MPa})$, based on the method described of Harris (1981). The osmotic potentials were chosen to simulate those found in ripening berries (Diakou et al. 1997; Tyerman et al. 2004). Three vineyard-isolated Botrytis cinerea strains (collected on 21/01/2008 and stored in $50 \%$ glycerol at $-80^{\circ} \mathrm{C}$ ) were grown on MEA for ten days and spore suspensions were made for each strain to a concentration of $1 \times 10^{5}$ spores/ $\mathrm{mL}$. Aliquots $(5 \mu \mathrm{L})$ of each spore solution were pipetted onto the centre of each of three MEA plates for each osmotic potential amended with $100 \mathrm{ppm}$ streptomycin (total of 45 plates) for 7 days under fluorescent lights (12 h light/12 h dark). Colony diameters were measured at 1, 2, 5 and $7 \mathrm{~d}$, and the mean growth rates per day were calculated. 


\section{Weather variables}

Weather monitoring equipment was set up inside the canopy of a grapevine under the additional shelter and inside the canopy of a grapevine outside the shelter. Sensors installed consisted of the following: one CS215 temperature and relative humidity $(\mathrm{RH})$ probe (Campbell Scientific, Logan, UT, USA) under the shelter and inside the grapevine canopy; one CS215 temperature/RH probe outside the shelter and inside the canopy; and one TR-252M 0.1-mm rain gauge (Texas Electronics, Dallas, TX, USA) under the shelter and outside the canopy. Data were also collected from one CS215 temperature/ $\mathrm{RH}$ probe and one TR-525M rain gauge attached to the Plant \& Food Research weather station located immediately adjacent to the vineyard on open grass.

Temperature and $\mathrm{RH}$ values for vines sheltered for different periods of time were calculated using data from sensors under the shelter and inside the canopy during sheltering, and outside the shelter and inside the canopy before and after sheltering. Rainfall values for vines sheltered for different periods of time were calculated using data from under the shelter during sheltering and from the weather station before and after sheltering.

\section{Soluble solids content}

Soluble solids content ( $\left.{ }^{\circ} \mathrm{Brix}\right)$ was measured for each plot at harvest (18/04/2017). Ten-berry samples were collected for each plot by arbitrarily selecting a single berry from each of ten bunches in each plot and placing all ten berries in a single plastic bag. The berries were squashed in the bag and soluble solids concentration of the juice was measured using aPAL-1 digital refractometer (Atago Co., Ltd, Tokyo, Japan).

\section{Botrytis bunch rot assessments}

Bunches were assessed in situ for botrytis bunch rot using image analysis. A blue pillowcase was placed over the assessors hand and positioned behind each bunch to obscure as much of the background as possible, and the bunch was photographed using an iPhone 6 (Apple, Cupertino, CA, USA). Images were then processed using Fiji image processing software (Schindelin et al. 2012) to remove all background, and leave only the bunch and blue background in each image. Processed images were analysed using a PC-based version of RotBot ${ }^{\mathrm{TM}}$ (Hill et al. 2014a).

Botrytis bunch rot was assessed at approximately weekly intervals on the following dates: 21/03/2017, 30/03/2017, 04/04/2017, $11 / 04 / 2017$, and $18 / 04 / 2017$. The final assessment was considered to correspond with vintage in a commercial vineyard despite low sugar content $\left(\right.$ Brix $\left.=17 \cdot 1^{\circ}\right)$. At this time, bunches were removed from each vine and placed on a blue background sheet on the ground and photographed for image analysis.

\section{Slip skin assessments}

Bunches collected for the final BBR assessment were placed in individual plastic bags labelled with respective plot numbers, vine sheltering condition and bunch number, and transported to the laboratory. A berry was considered to have slip skin if, when gently squeezed, the skin came off the berry leaving the pulp and seeds attached to the rachis. Because of the difficulty of detecting and quantifying slip skin and the time required to assess every berry, each bunch was assessed using an adaptive sampling method to produce a 'slip skin score'. The method was carried out as follows using arbitrarily chosen berries: 1) individual berries were assessed for slip skin sequentially keeping track of berry count; 2) if 10 berries were assessed and none had slip skin, assessment ended and the score $=0$, otherwise if a berry had slip skin, the berry count was reset and further berries were assessed; 3 ) if a further 10 berries were assessed and none had slip skin, assessment ended and the score $=1$, otherwise if a second berry had slip skin, the berry count was reset and further berries were assessed; 4) if a further 10 berries were assessed and none had slip skin then the assessment ended and the score $=2$, otherwise if a third berry had slip skin, then assessment ended and the score $=3$. This resulted in the assessment of $3-30$ berries and a slip skin score ranging from $0-3$ for each bunch. Number of berries assessed was not recorded. 


\section{Statistical analyses}

Statistical analyses were carried out using R Studio (version 1.0.143; R Studio Team 2016) running $\mathrm{R}$ (version 3.3.2; R Core Team 2016). Additional packages used included: 'readxl' for data importation (Wickham \& Bryan 2017), 'lubridate' for manipulating date values (Grolemund \& Wickham 2011), 'tidyverse' for data manipulation and organisation (Wickham 2016), 'agricolae' for mean comparisons (Mendiburu 2016), 'ggplot2' for figure production (Wickham 2009). Default values were used for all analyses.

Botrytis bunch rot percentage severity data were logit-transformed to satisfy the assumptions of normality and homogeneity of variance before analysis using the following equation:

$$
\mathrm{f}(x)=\ln ((x+0.1) /(100.1-x)),
$$

where $x=$ percentage BBR severity. Logittransformed BBR data were used in analysis of variance (ANOVA), mean comparisons and as covariates for analyses involving slip skin scores.

\section{RESULTS}

\section{In vitro growth of Botrytis cinerea on osmotically adjusted agar}

The growth rate of B. cinerea on osmotically adjusted MEA decreased with decreasing osmotic potential, from a mean of $16.8 \mathrm{~mm} /$ day at $-0.5 \mathrm{MPa}$ to $10.9 \mathrm{~mm} /$ day at $-4 \mathrm{MPa}$ (Figure 1). All three strains followed the same trend of decreasing growth with decreasing osmotic potential, therefore their data were combined and differences represented in the error bars.

\section{Effects of sheltering on weather-related variables}

Sheltering did not substantially affect mean, minimum or maximum temperature, or mean hours per day with RH greater than $80 \%$ (Table 1). Vines sheltered from the time of flowering onwards were exposed to a reduction in total rainfall of $420.3 \mathrm{~mm}$, those sheltered from the time of $\mathrm{PBC}$ onwards received $355.5 \mathrm{~mm}$ less rain, and those sheltered from the time of véraison received $265.2 \mathrm{~mm}$ less rain than unsheltered vines.

\section{Botrytis bunch rot epidemics}

Irrespective of the period that the shelters were in place, sheltering resulted in reduced mean percentage BBR severity at all assessment dates, although BBR epidemics in all the vines developed at a similar rate (Figure 2). Mean BBR severity in sheltered vines was significantly lower $(\mathrm{P}<0.05)$ than in partially sheltered and unsheltered vines prior to shelter removal, but was not significantly different from that in partially sheltered vines at harvest (Figure 2).

\section{Harvest assessments}

The overall mean soluble solids content ( ${ }^{\circ}$ Brix) for grape berries harvested from the trial was 17.1 , which was very low compared with common commercial targets for Sauvignon blanc of $21.5^{\circ}$. Brix values in sheltered vines were significantly lower $(\mathrm{P}<0.05)$ than those in either unsheltered or partially sheltered vines (Table 2). Timing of shelter installation did not significantly affect soluble solids content (Table 3 ).

The overall mean BBR severity for the trial was $40.8 \%$. Mean BBR severity at harvest was

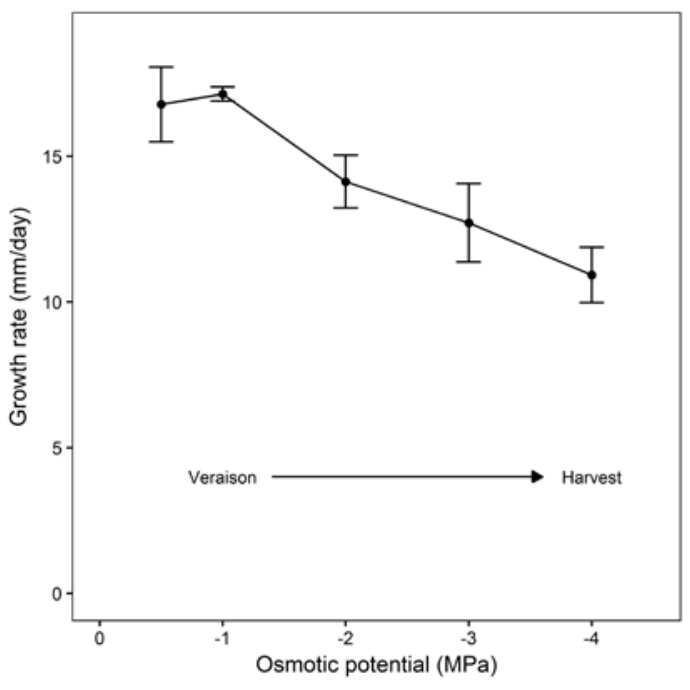

Figure 1 Overall mean growth rates for three strains of Botrytis cinerea on malt extract agar (MEA) with different osmotic potentials. The increase in osmotic potential of grape berry juice during ripening from véraison to harvest is also shown. 
Table 1 Date of shelter installation at three Sauvignon blanc grapevine phenological stages and mean weather-related parameters calculated between budburst (07/12/2016) and harvest (18/04/2017). Minimum and maximum temperatures are mean daily values.

\begin{tabular}{lcccc}
\hline Variable & Unsheltered & $\begin{array}{c}\text { Flowering } \\
\text { onwards }\end{array}$ & $\begin{array}{c}\text { PBC }^{*} \\
\text { onwards }\end{array}$ & $\begin{array}{c}\text { Véraison } \\
\text { onwards }\end{array}$ \\
\hline Shelter installation date & - & $20 / 12 / 2016$ & $25 / 01 / 2017$ & $21 / 02 / 2017$ \\
Number of days sheltered & & 105 & 69 & 42 \\
Total rainfall $(\mathrm{mm})$ & 599.2 & 178.9 & 243.7 & 334.0 \\
Mean temperature $\left({ }^{\circ} \mathrm{C}\right)$ & 17.8 & 17.6 & 17.7 & 17.7 \\
Minimum temperature $\left({ }^{\circ} \mathrm{C}\right)$ & 12.9 & 12.9 & 12.9 & 12.9 \\
Maximum temperature $\left({ }^{\circ} \mathrm{C}\right)$ & 24.0 & 23.5 & 23.7 & 23.8 \\
Mean hours/day $\mathrm{RH}^{\ddagger} \geq 80 \%$ & 15.0 & 15.0 & 15.0 & 15.0 \\
\hline
\end{tabular}

${ }^{\star}$ Pre-bunch closure. ${ }^{\dagger}$ All shelters were removed on $04 / 04 / 2017$. ${ }^{\star}$ Relative humidity.

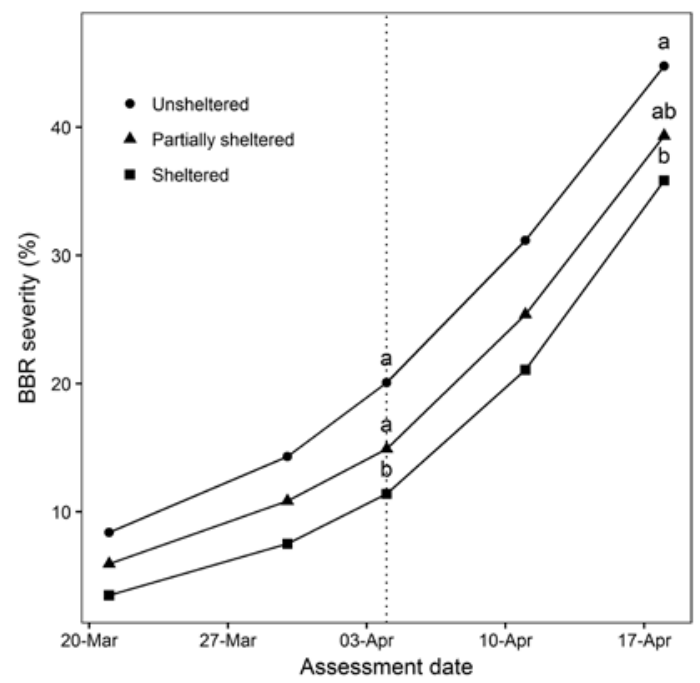

Figure 2 Epidemic progress curves for botrytis bunch rot (BBR) severity in unsheltered, partially sheltered and sheltered Sauvignon blanc grapevines. The vertical dotted line indicates the date of removal of all shelters (04/04/2017). Means on the same assessment date (04/04/2017 and 18/04/2017) with the same letter indicate treatment means are not significantly different $(\mathrm{P}>0.05)$. Analyses were carried out only for those dates where letters are shown. significantly reduced $(\mathrm{P}<0.05)$ in sheltered vines compared with that in unsheltered vines (Table 2). Timing of shelter installation did not significantly affect BBR severity (Table 3 ).

The overall mean slip skin score for the trial was 1.8. Mean slip skin scores at harvest were significantly increased $(\mathrm{P}<0.05)$ in sheltered vines compared with scores in partially sheltered vines (Table 2). Mean slip skin score was reduced $(\mathrm{P}<0.05)$ in vines sheltered at véraison compared with that in vines sheltered from PBC (Table 3). Mean incidences of bunches exhibiting slip skin symptoms at harvest were $71.8 \%$ for unsheltered vines, $71.1 \%$ for partially sheltered vines, and $77.5 \%$ for sheltered vines.

Logit-transformed BBR severity and slip skin scores for all plots at harvest were significantly correlated $\left(y=-0.619 x+0.662 ; \mathrm{R}^{2}=0.517\right.$; $\mathrm{P}<0.001)$.

\section{DISCUSSION}

Manipulating weather conditions to alter disease development in vineyards is difficult, particularly in a manner that allows for statistical rigour in field experiments. This study attempted to achieve this through the installation of vine shelters to reduce rainfall and to investigate effects on the development of botrytis bunch rot (BBR) and slip skin symptoms due to Botrytis cinerea infection. 
Table 2 Mean botrytis bunch rot (BBR) severity, slip skin scores and soluble solids contents for unsheltered $(n=18)$, partially sheltered $(n=18)$, and sheltered $(n=9)$ Sauvignon blanc grapevines at harvest (18/04/2017). The means are adjusted based on the indicated covariates used in the analyses. Means followed by the same letter in each column are not significantly different $(\mathrm{P}<0.05)$.

\begin{tabular}{lccc}
\hline Sheltering condition & BBR severity $(\%)^{*}$ & Slip skin score ${ }^{\dagger}$ & $\begin{array}{c}\text { Soluble solids content } \\
\left({ }^{\circ} \text { Brix }\right)\end{array}$ \\
\hline Unsheltered & $44.8 \mathrm{a}$ & $1.9 \mathrm{ab}$ & $17.6 \mathrm{a}$ \\
Partially sheltered & $39.3 \mathrm{ab}$ & $1.7 \mathrm{~b}$ & $17.1 \mathrm{a}$ \\
Sheltered & $35.8 \mathrm{~b}$ & $2.2 \mathrm{a}$ & $16.0 \mathrm{~b}$ \\
\hline
\end{tabular}

${ }^{\star}$ Brix values used as covariates in analyses; ${ }^{\dagger}$ Brix values and BBR severity used as covariates in analyses.

Table 3 Mean botrytis bunch rot (BBR) severity, slip skin scores and soluble solids contents for Sauvignon blanc grapevines sheltered from three phenological stages $(n=15)$ at harvest $(18 / 04 / 2017)$. Means followed by the same letter in each column are not significantly different $(\mathrm{P}<0.05)$. Data from unsheltered vines were not included in the analysis as sheltering would not have affected these vines regardless of installation date.

\begin{tabular}{lccc}
\hline $\begin{array}{l}\text { Time of shelter } \\
\text { installation }\end{array}$ & BBR severity $(\%)^{*}$ & ${\text { Slip skin score }{ }^{\dagger}}^{*}$ & $\begin{array}{c}\text { Soluble solids content } \\
\left({ }^{\circ} \text { Brix }\right)\end{array}$ \\
\hline Flowering & $37.2 \mathrm{a}$ & $1.9 \mathrm{ab}$ & $16.7 \mathrm{a}$ \\
Pre-bunch closure & $39.6 \mathrm{a}$ & $2.2 \mathrm{a}$ & $16.1 \mathrm{a}$ \\
Véraison & $45.6 \mathrm{a}$ & $1.5 \mathrm{~b}$ & $17.1 \mathrm{a}$ \\
\hline
\end{tabular}

${ }^{\star}$ Brix values used as covariates in analyses; ${ }^{\dagger}$ Brix values and BBR severity used as covariates in analyses.

The growth rate of $B$. cinerea on osmotically adjusted media was progressively reduced when osmotic potential of the agar growth medium also decreased. This result indicates that the osmotic potential of grape berries, which decreases between véraison and harvest due to increasing sugar concentrations, would increasingly inhibit the growth of $B$. cinerea as harvest approaches. If this were the case, the rate of increase of the BBR epidemic would reduce as the grape berries ripened. However, the opposite is typically the case in seasons that are conducive to a BBR epidemic (Beresford et al. 2006). This finding suggests that other factors negate the inhibitory effects of decreasing osmotic potential, supporting the hypothesis that late-season rainfall dilutes berry sugars, increasing osmotic potential and subsequently $B$. cinerea growth. Berry sugar concentration has been found to be positively correlated with $B$. cinerea infection rates (Mundy \& Beresford 2007), and infection can occur during berry ripening (Hill et al. 2014b). Berry tissues and anti-fungal compounds within the berry (Pezet et al. 2003) both degrade during ripening. These processes could account for typical BBR development, while the majority of latent infections remain inhibited until berry sugar concentration is sufficiently diluted by lateseason rainfall to allow rapid fungal growth.

There was a relationship between vine sheltering and BBR severity, but the rate of epidemic increase was not affected during sheltering. The reduction in the differences in percentage BBR severity between sheltered vines and either partially sheltered or unsheltered vines once shelters were removed could have resulted from a similar number of latent infections occurring prior to shelter removal that were inhibited until exposure to late-season rainfall. Soluble solids content was not measured with a 
degree of precision great enough to determine whether this disease increase was associated with decreases in berry sugar concentration. Brix values were lower in sheltered vines, probably because of reduced exposure to sunlight (Smart \& Robinson 1991). Osmotic potential would, therefore, have been lower, leading to inhibition of latent infections.

Timing of the installation of vine shelters did not influence BBR severity at harvest, despite vines being exposed to substantially different rainfall amounts during the season. Botrytis bunch rot epidemics are heavily influenced by seasonal accumulations of leaf wetness (strongly correlated with RH) and temperature (Beresford \& Hill 2008). Since temperature and $\mathrm{RH}$ were not affected by sheltering in the field trial, it is likely that latent infection rates and the potential risk of BBR were similar for all vines prior to lateseason rainfall influencing the BBR epidemic. It is also possible that the heavy BBR severities in all the treatments, as well as other bunch rots that were developing during ripening, masked some of the treatment effects, as there was an $8 \%$ difference in severity between the flowering and véraison treatments.

Slip skin was also influenced by vine sheltering, with sheltered vines having higher slip skin scores than partially sheltered vines at harvest. This suggests that the longer latent $B$. cinerea infections are inhibited prior to being exposed to rainfall, the more likely they are to result in slip skin rather than BBR symptoms. This supports the hypothesis that slip skin is the result of inhibited latent infections becoming activated by late-season rainfall. However, slip skin score for unsheltered vines was not significantly different to sheltered vines, and the amount of latent infection was not measured so could not be ruled out as a confounding variable. Therefore, this conclusion can't be drawn definitively without further clarification. Timing of shelter installation also affected slip skin scores, with vines sheltered from véraison having lower mean slip skin scores than those sheltered from PBC onwards. This result also supports the hypothesis that latent infections occur at steady rates because of seasonal temperatures and $\mathrm{RH}$, but irrespective of rainfall. The more the berries that contain these infections are exposed to rainfall, the more likely they are to express disease as BBR rather than slip skin. As mentioned above in relation to BBR symptoms, it is possible these differences would have been more pronounced if slip skin incidence were lower than $70 \%$ for all treatments. It is proposed that the slip skin scoring method used in this study is modified to include a range of 0 to 5 in future slip skin studies. This will give greater precision to assessment of the intensity of slip skin symptoms, potentially improving treatment separation.

The season in which this study was carried out was extremely wet compared with the long-term average rainfall for Auckland (NIWA 2017). This resulted in large differences in rainfall between the sheltered and unsheltered vines. Nevertheless, this meant that the overall BBR epidemic was very severe. The severe BBR epidemic potentially masked and reduced the chance of identifying slip skin symptoms, because the more berries on bunches that are rotting or sporulating would result in fewer berries remaining to exhibit slip skin symptoms.

This study has shown that manipulating rainfall using artificial shelters can influence BBR and slip skin symptoms. However, because of the high rainfall and low soluble solids contents encountered in this trial, the study should be repeated in another year at a vineyard with the potential to reach a higher soluble solids content so that treatment differences can be better separated. The effect of late-season rainfall on berry sugar concentration, and the period over which this effect occurs, should also be studied by precisely monitoring soluble solids content in sheltered vines, and the subsequent effect on osmotic potential, before and after shelter removal or through targeted irrigation, as this remains a key knowledge gap in the osmoticpotential hypothesis. Despite the issues faced and the knowledge gaps that remain, there is evidence that latent $B$. cinerea infections are inhibited until the infected berries are exposed to rainfall. If this occurs prior to the increase in berry sugar 
concentration during ripening, the infections are more likely to express as BBR, but if the berries are not exposed to rainfall until after sugars have increased to an inhibitory concentration, they are more likely to express as slip skin symptoms.

\section{ACKNOWLEDGEMENTS}

This work is part of the Plant \& Food Research (PFR) Grape and Wine Research programme, funded by the MBIE Strategic Science Investment Fund (SSIF), and delivered by PFR in consultation with New Zealand Winegrowers.

We thank Mr Peter Wright and Mr Moe Jeram for maintaining the Pukekohe research vineyard and assisting with disease assessments.

\section{REFERENCES}

Becker T, Grimm E, Knoche M 2012. Substantial water uptake into detached grape berries occurs through the stem surface. Australian Journal of Grape and Wine Research 18: 109-114.

Beever RE, Laracy EP 1986. Osmotic adjustment in the filamentous fungus Aspergillus nidulans. Journal of Bacteriology 168: 1358-1365.

Beresford RM, Hill GN 2008. Botrytis control without fungicide residues - is it just a load of rot? New Zealand Winegrower 12: 104-106.

Beresford RM, Evans KJ, Wood PN, Mundy DC 2006. Disease assessment and epidemic monitoring methodology for bunch rot (Botrytis cinerea) in grapevines. New Zealand Plant Protection 59: 355-360.

Bondada BR, Matthews MA, Shackel KA 2005. Functional xylem in the post-véraison grape berry. Journal of Experimental Botany 56: 2949-2957.

Choat B, Gambetta GA, Shackel KA, Matthews MA 2009. Vascular function in grape berries across development and its relevance to apparent hydraulic isolation. Plant Physiology 151: 1677-1687.

Clarke SJ, Hardie WJ, Rogiers SY 2010. Changes in susceptibility of grape berries to splitting are related to impaired osmotic water uptake associated with losses in cell vitality. Australian Journal of Grape and Wine Research 16: 469-476.
Diakou P, Moing A, Svanella L, Ollat N, Rolin DB, Gaudillere M, Gaudillere JP 1997. Biochemical comparison of two grape varieties differing in juice acidity. Australian Journal of Grape and Wine Research 3: 1-10.

Grolemund G, Wickham H 2011. Dates and times made easy with lubridate. 2011 40: 25.

Harris RF 1981. Effect of water potential on microbial growth and activity. In: Parr JF, Gardner WR, Elliott LF eds. Water Potential Relations in Soil Microbiology. SSSA Special Publication. Soil Science Society of America. Pp. 23-95.

Hill GN, Beresford RM, Evans KJ 2010. Tools for accurate assessment of botrytis bunch rot (Botrytis cinerea) on wine grapes. New Zealand Plant Protection 63: 174-181.

Hill GN, Evans KJ, Beresford RM, Dambergs RG 2014a. Comparison of methods for the quantification of botrytis bunch rot in white wine grapes. Australian Journal of Grape and Wine Research 20: 432-441.

Hill GN, Evans KJ, Beresford RM 2014b. Use of nitrate non-utilising (nit) mutants to determine phenological stages at which Botrytis cinerea infects wine grapes causing botrytis bunch rot. Plant Pathology 63: 13161325.

Keller M, Smith JP, Bondada BR 2006. Ripening grape berries remain hydraulically connected to the shoot. Journal of Experimental Botany 57: 2577-2587.

Loschiavo A, Scholefield P, Morrison J, Ferris M 2010. The cost of pests and diseases to the Australian winegrape industry. Australian Viticulture 14: 15-19.

McCarthy MG, Coombe BG 1999. Is weight loss in ripening grape berries cv. Shiraz caused by impeded phloem transport? Australian Journal of Grape and Wine Research 5: 17-21. Mendiburu Fd 2016. agricolae: Statistical Procedures for Agricultural Research. https:// CRAN.R-project.org/package=agricolae.

Mundy DC, Beresford RM 2007. Susceptibility of grapes to Botrytis cinerea in relation to berry nitrogen and sugar concentration. New Zealand Plant Protection 60: 123-127. 
Nelson KE 1956. The effect of Botrytis infection on the tissue of Tokay grapes. Phytopathology 46: 223-229.

NIWA 2017. Mean monthly rainfall (mm). https://www.niwa.co.nz/education-andtraining/schools/resources/climate/meanrain (05-05-2017).

Pezet R, Viret O, Perret C, Tabacchi R 2003. Latency of Botrytis cinerea Pers.: Fr. and biochemical studies during growth and ripening of two grape berry cultivars, respectively susceptible and resistant to grey mould. Journal of Phytopathology 151: 208-214.

R Core Team 2016. R: A language and environment for statistical computing. $\mathrm{R}$ Foundation for Statistical Computing, Vienna, Austria. https://www.R-project.org/.

R Studio Team 2016. RStudio: Integrated Development for R. RStudio, Inc., Boston, MA. http://www.rstudio.com/.

Rogiers SY, Smith JA, White R, Keller M, Holzapfel BP, Virgona JM 2001. Vascular function in berries of Vitis vinifera (L) cv. Shiraz. Australian Journal of Grape and Wine Research 7: 47-51.

Schindelin J, Arganda-Carreras I, Frise E, Kaynig V, Longair M, Pietzsch T, Preibisch S, Rueden C, Saalfeld S, Schmid B, Tinevez J-Y, White DJ, Hartenstein V, Eliceiri K, Tomancak P, Cardona A 2012. Fiji: an open-source platform for biological-image analysis. Nature Methods 9: 676-682.
Smart R, Robinson M 1991. Sunlight into Wine. Winetitles, Adelaide, Australia.

Taiz L, Zeiger E 1998. Plant Physiology. Sinauer Associates, Sunderland, MA, USA.

Tyerman SD, Tilbrook J, Pardo C, Kotula L, Sullivan W, Steudle E 2004. Direct measurement of hydraulic properties in developing berries of Vitis vinifera L. cv Shiraz and Chardonnay. Australian Journal of Grape and Wine Research 10: 170-181.

Whiting EC, Rizzo DM 1999. Effect of water potential on radial colony growth of Armillaria mellea and A. gallica isolates in culture. Mycologia 91: 627-635.

Wickham H 2009. ggplot2: Elegant Graphics for Data Analysis. Springer-Verlag New York.

Wickham H 2016. tidyverse: Easily Install and Load 'Tidyverse' Packages. https://CRAN.Rproject.org/package $=$ tidyverse.

Wickham H, Bryan J 2017. readxl: Read Excel Files. https:/CRAN.R-project.org/ package $=$ readxl.

Wilcox WF, Gubler WD, Uyemoto JK 2015. Compendium of Grape Diseases, Disorders, and Pests: Second Edition. APS Press, St Paul, MN, USA. 